\title{
Hyperactivity and creativity: The tacit dimension
}

\author{
GERALDINE A. SHAW \\ Georgetown College, Georgetown, Kentucky
}

\begin{abstract}
Discriminant analysis was performed on the combined data from two previous studies of high-IQ children with attention disorder and hyperactivity. The variables that best discriminated these from normal children were left-sided laterality, the ability to perceive coherence tacitly, the use of incidentally acquired information, stimulation seeking, and the use of imagery in problem solving and in a creativity task. Regression analysis indicated that figural creativity is best predicted by the ability to perceive relationships tacitly, by good memory for pictured objects, and by verbal creativity. A model was proposed to help explain the functioning of intelligent and creative attention-disordered individuals.
\end{abstract}

In discussing the biology of cerebral dominance, Geschwind (1984) noted a "pathology of superiority" in the relationship between special "right hemisphere functions," learning disorders, higher levels of sinistrality, and allergies. A similar lateralization of function model (Levy, 1983) suggests that the left hemisphere is basically analytic, sequential, and linguistic, whereas the right is spatial, synthetic, attentional, and imagistic. Levy cites evidence that the right hemisphere is capable of highly complex cognitive processes, and that it is superior in the processes that are visuospatial and geometric, that facilitate classification of non-nameable objects in concept formation, and that extract set-defining characteristics.

The present analysis includes data from two previous studies examining Geschwind's (1984) hypothesis that talents associated with right hemisphere processing will be seen in children with learning disorders. The cognitive processes investigated here have previously been linked to both creativity and attention deficit/hyperactivity disorder (ADHD). Also examined are traits identified by Ross and Ross (1982) for ADHD children and by Sternberg (1985) for creative people, such as high curiosity levels, impulsivity, high risk taking, and high activity levels.

\section{Creativity}

Although no universal acceptance of a definition or measurement of the creative process exists, Getzels (1975) proposed that thinking may be called creative if it is unconventional and has great intensity, and if it formulates the problem itself and yields a novel, useful product. The process of creative thinking was first described by Wallas (1927) as being composed of four stages: preparation (hard, conscious work), incubation (involuntary, unconscious work), illumination (a flash of insight), and verification

\footnotetext{
I am grateful to the Department of Behavioral Science of the University of Kentucky College of Medicine for extending their facilities to me during my sabbatical leave, during which this paper was written. Correspondence should be addressed to G. A. Shaw, Department of Psychology, Georgetown College, Georgetown, KY 40324.
}

(a second period of conscious work). Yaniv and Meyer (1987) found that incubation involves an increased likelihood of successful solution of a problem as a result of a delay between a period of work on a problem and the subsequent coalescence of mental elements that together solve the problem. They encouraged the study of spreading activation effects (using indirect criterion tasks) on how problem solutions are generated by people integrating diverse bits of implicit information. In discussing the roles of tacit and explicit knowledge in the creative process, Bolton (1972) mentioned the use of incidental cues in problem solving, wide scanning attention deployment, and diffuse awareness.

Studies of the cognitive processes of creative individuals suggest that high creatives report and use more imagery and that hypermnesia is stronger in highly creative subjects than in low creatives (see Shaw, 1986). Using a remote-associates test of creativity, Bowers (1984) found stable individual differences in the ability to perceive coherence tacitly. Shaw and Conway (1990) found that highly creative subjects used more nonconscious clues in solving anagrams and had lower thresholds for processing nonconscious information than did low creatives. Earlier work by Mendelsohn and Griswold (1964) showed that highly creative subjects who used incidental clues of which they were unaware solved anagrams to a greater degree than did low creative subjects.
ADHD
Douglas (1983) concluded that ADHD children perform more poorly than normal children in tasks requiring sus- tained attention, but paradoxically, that they do very well in high-interest situations. She suggested that basic atten- tional difficulties come from poor organization and in- vestment of effort and argued that low-effort tasks are preferred by ADHD children because they fail "to ex- tend the additional effort required"' in demanding tasks. However, Borcherding et al. (1988) found no differences in automatic processing between ADHD children and nor- mal children, although the normal children were better in effortful or controlled aspects of their tasks. Similarly Rutter (1989) suggested that ADHD children have dif- 
ficulty inhibiting actions and that they are not necessarily more easily distracted than normal children.

Douglas (1983) reported that some, but not all, ADHD children show cortical underarousal and are underreactive to environmental stimuli, and that most ADHD children function outside of their optimal range of arousal most of the time. These children are underaroused in dull tasks and supraoptimally aroused in interesting tasks. In a similar vein, Zentall and Zentall (1983) proposed a model of optimal stimulation for attention-disordered and other deviant children. However, arousal levels do not explain the information-gathering abilities of these children.

\section{The Present Analysis}

Data from two previous studies were combined for this report. In one study, in Norfolk, England (Shaw \& Brown, 1990), teachers selected high-IQ, attention-disordered, hyperactive (ADH) schoolchildren and matched them for age, sex, and IQ with normal children, while in another study of high-IQ children in Kentucky (Shaw, 1989; Shaw \& Brown, 1991), the Conners Abbreviated Teacher Rating Scale (Conners, 1973) was used to determine subject and matched control group selection. (Note that ADHD refers to a clinically diagnosed condition, while $\mathrm{ADH}$ designates subjects who were selected by their teachers.) With the exception of a more elaborate allergy scale (Shaw, 1989), the same measures were employed in both studies.

\section{METHOD}

\section{Subjects and Design}

The subjects from two studies were pooled so that the ADH children from both studies made up the experimental group and normal subjects (matched for age, sex, and IQ) from both groups made up the control group. Discriminant and multiple-regression analyses were conducted on the variables that were measured with the same instruments in both studies.

\section{Materials and Procedure}

The variables measured were: laterality, tacit coherence of relationships, use of incidental information in solving anagrams, free recall of focal and peripheral objects, creativity, incidental memory, problemsolving style, and stimulation seeking. (See Shaw \& Brown, 1990, for a more complete description of the method.) Tasks measuring these variables were administered in the following order:

1. Laterality was established with $\mathbf{1 0}$ common skills (writing, kicking, viewing through a hole in a card, etc.), each of which was assessed twice. Scores between +20 (right side) and -20 (left side) indicated the degree of predominance of laterality of function.

2. Tacit coherence of relationships was measured by showing the children groupings of related or unrelated objects pictured on stimulus cards as central and peripheral objects. Tasks $2-4$ were interrelated so that peripherally embedded in Task 2 were 10 objects, which, unknown to the subjects, were solutions to the anagrams in Task 3 . These pictures were meant to prime or activate memory traces of these objects to aid subjects in their anagram solving. Six related groupings of objects were constructed on the basis of common word association norms, while six groupings were randomly chosen words. The children were asked to focus on the central object for $1 \mathrm{sec}$ and then to state whether the grouping was related or not. The score for this task was the number of groups correctly identified as related or unrelated.

3. Anagram solving was employed to determine whether the subjects could use incidentally acquired information in subsequent problemsolving situations. The 10 simple, five-letter anagrams, which were presented without time limitation, had solution words that corresponded to 10 of the peripheral objects in Task 2 . The score for Task 3 was the number of anagrams solved. Also recorded were the numbers of sec- onds needed to solve the anagrams or the number of seconds taken for each anagram until the child gave up.

4. After all anagrams had been presented, the children were asked to recall as many of the objects on the picture group cards as possible. Scores were the numbers of focal and peripheral objects remembered.

5. Creativity was measured by administering two subtests, one figural (circles) and one verbal (just suppose) from the Torrance Tests of Creative Thinking (Torrance, 1974).

6. Incidental memory was tested by showing subjects a series of 10 pictures of farm animals in similar, yet slightly different, backgrounds, and then showing the subjects only the backgrounds with the animals removed and asking the subjects to tell which animal belonged in each picture.

7. Problem solving was determined by asking subjects to solve a "Monster" version of the Tower of Hanoi problem. The children were given blank pages of paper and asked to show how they would solve the problem. Their responses were rated on a continuum from picture/symbol use only (5 points) to use of only words/letters/numbers (1 point; see Shaw, 1985).

8. Stimulation seeking was self-reported on the Stimulation Seeking Questionnaire for Children, which comprised 24 items similar to those in Zuckerman's Sensation Seeking Scale, Form V (1979). The score for this test was the number of responses showing greater stimulation seeking.

\section{RESULTS}

Discriminant analysis was performed on the data massed from the two studies. Discriminant function values were: Wilk's $\lambda=.26, \chi^{2}=70.76, d f=14$, and $p<.0001$. Means and standard deviations for all variables are summarized in Table 1. The results of discriminant analysis (see Table 1) showed that the variables that discriminate between the groups best (descending in order of significance within the single function found) are laterality, the ability to perceive relationships tacitly, crossed eye-hand dominance, time spent with unsolved anagrams, figural creativity, sensation seeking, incidental memory, the use of imagery in problem solving, and the use of peripheral information to solve anagrams. The variables that did not

Table 1

Discriminant Analysis Statistics

\begin{tabular}{|c|c|c|c|c|c|c|c|}
\hline \multirow[b]{3}{*}{ Variable } & \multirow[b]{3}{*}{$\lambda$} & \multirow[b]{3}{*}{$F(1,62)$} & \multirow[b]{3}{*}{$p<$} & \multicolumn{4}{|c|}{ Group } \\
\hline & & & & \multicolumn{2}{|c|}{$\mathrm{ADH}$} & \multicolumn{2}{|c|}{ Control } \\
\hline & & & & $M$ & $S D$ & $M$ & $S D$ \\
\hline Laterality & 0.73 & 21.8 & .0001 & 7.0 & 6.8 & 15.3 & 6.6 \\
\hline Tacit coherence & 0.80 & 14. & .0003 & 10.1 & 1.0 & 8.7 & 1.7 \\
\hline Eye dominance* & 0.82 & 12.4 & .0008 & 1.5 & 0.5 & 1.9 & 0.3 \\
\hline $\begin{array}{l}\text { Reaction time ana- } \\
\text { grams not solved }\end{array}$ & 0.83 & 12.1 & .0009 & 28.6 & 8.7 & 38.7 & 14.3 \\
\hline Circles & 0.84 & 11. & .001 & 56.5 & 15.2 & 42.1 & 16.5 \\
\hline $\begin{array}{l}\text { Stimulation Seeking } \\
\text { Questionnaire for } \\
\text { Children }\end{array}$ & 0.84 & 11.4 & .001 & 17.2 & 3.4 & 14.1 & 3.8 \\
\hline Incidental memory & 0.84 & 11.1 & .002 & 4.4 & 1.5 & 3.1 & 1.8 \\
\hline Monster prob & 0.90 & & .01 & 3.1 & 1.5 & 2.1 & 1.4 \\
\hline Anagrams solved & 0.93 & 3.8 & .05 & 3.8 & 2.1 & 2.7 & 1.5 \\
\hline $\begin{array}{l}\text { Recall of focal } \\
\text { objects }\end{array}$ & 0.96 & 2.1 & .16 & 4.3 & 1.5 & 4.8 & 1.5 \\
\hline $\begin{array}{l}\text { Reaction time } \\
\text { anagrams solved }\end{array}$ & 0.98 & 0.6 & .43 & 15.8 & 6.1 & 14.5 & 8.3 \\
\hline Suppose & 0.99 & 0 & .91 & 22.0 & 10.5 & 23.1 & 9.1 \\
\hline $\begin{array}{l}\text { Recall of peripheral } \\
\text { objects }\end{array}$ & 0.99 & 0.5 & .94 & 1.8 & 1.8 & 1.6 & 1.9 \\
\hline Country & 1.00 & 0.0 & 1.0 & & & & \\
\hline
\end{tabular}

Note-ADH $=$ attention-disordered, hyperactive children. $\quad{ }^{*}$ Crossed eye-hand dominance $=1$; same eye-hand dominance $=2$. 
discriminate between groups were recall of focal objects, reaction time in solving anagrams, verbal creativity, and recall of peripheral objects. The percentage of cases correctly classified in this analysis was $\mathbf{9 0 . 6 \%}$.

To determine the predicting factors of figural creativity, the data from subjects of both groups were combined and submitted to multiple-regression analysis with figural creativity as the dependent variable and tacit coherence, number of anagrams solved, reaction times for solved and unsolved anagrams, recall of focal and peripheral objects, incidental memory, the monster problem, sensation seeking, intelligence, age, crossed eye-hand dominance, and laterality as independent variables. The factors that proved to be significant predictors of figural creativity were (a) recalling focal objects $(p<.01)$, (b) tacit perception of relationships $(p<.04)$, and (c) verbal creativity $(p<.04)$. The underlying commonality between verbal and figural creativity (factor c) and the link between imagery memory and creativity (factor a) have been reported in previous studies (Shaw, 1985, 1986). Interestingly, the ability to perceive relationships tacitly (factor $b$ ) is the only variable that both predicts figural creativity and discriminates $\mathrm{ADH}$ children from normal children. This supports Bolton's (1972) conclusion that the ability to tacitly gather information is of importance in the creative process.

\section{DISCUSSION}

The analysis of data from two studies has provided further evidence that high-IQ, attention-disordered children deal with the world in a manner that is cognitively and behaviorally different from that of normal highIQ children. If evidence of imagery-based creativity can be considered unusual talent, these results can be seen as support for Geschwind's theory that a high degree of talent will be found in learning-disordered individuals who show a higher degree of left-sidedness than most individuals. It appears that ADH children can process information and relationships in an unfocused interaction with the stimulus materials. They rely on nonverbal processes in meeting the demands of educational situations, although their verbal skills are not poor. Because of their inability to direct and sustain attention normally, hyperactives cope with environmental demands by acting on the basis of less complete or less fully conscious information. I suggest that $\mathrm{ADH}$ children generate unusual ideas from their somewhat diverse and idiosyncratic knowledge bases.

But how may the various factors from the present analysis and from other research reports be integrated to explain the creativity of intelligent, ADHD individuals? First, several observations will be given, and then various aspects of these points will be synthesized into a model of ADHD and creative behavior.

\section{Links Between Laterality and Cognitive Deviance}

A number of studies have demonstrated interconnections between laterality and such deviant cognitive and behavioral symptoms as those seen in schizophrenia, ADHD, dyslexia, stuttering, and autism. Of particular interest are reports of relationships between between left-eye dominance and learning disorders (see Denckla, 1979), childhood hyperactivity (see Zinbarg, 1987), and schizophrenia (see Merrin, 1984). The mechanisms controlling ocular dominance in relation to cognitive and behavioral deviancies have not been extensively explored, but the existence of many studies relating these factors warrants further research efforts.

Posner (1988) listed four disorders in which underlying neural damage is unknown but in which individuals are unable to concentrate or interact appropriately with the environment: depression, schizophrenia, closed head injury, and attention-deficit disorder. He used schizophrenia as a model in describing a pattern of right visual field deficit of attention (due to left hemisphere abnormality). Although in subjects with schizophrenia there is a right-visual-field reaction time deficit, Swanson et al. (1991) have shown that, for ADHD children, the right-visual-field reaction time is normal but the left-visual-field reaction time (right hemisphere) is abnormal in that it is faster than expected. Thus ADHD subjects have difficulty in maintaining attention, not in the usual sense of sustained attention during a vigilance task (15-60 min), but in the "rapid dissipation of focused attention which occurs over a very brief period $(800 \mathrm{msec})$."

\section{ADHD Individuals Have Impaired Cognitive Control}

Impulsivity is a common characteristic for both ADHD and highly creative people. Logan (1989) concluded that ADHD subjects have difficulty inhibiting some of their actions and do not gain control of automatic processes as readily as do normals. Posner and Rothbart (1989), in integrating much material on the varieties of automaticity, stated that "automatic processes seem most effective in governing behavior when the subject is otherwise occupied and thus less able to employ a qualifying context." They describe automatic operations as not limited in capacity and as occurring without intention and awareness. It seems fair to say that, given their attention problems, qualifying contexts are quite difficult for ADHDs to attain, and that they rely on automatic processes to a greater extent than do others. Indeed, there are many anecdotes of hyperactives operating on "automatic pilot."

\section{Boredom Is Aversively Stressful to \\ Creative and ADHD Persons}

Boredom intolerance is a factor common in high sensation seekers (Zuckerman, 1979), and both ADHD and creative individuals are represented in this category. Indeed, persistent, "driven" behavior is quite common in highly creative persons (Getzels, 1975). Understimulation is aversively stressful (Zentall \& Zentall, 1983) and may result in mental disorganization.

Shaw and Giambra (1991) examined the thought intrusions in attentiondisordered subjects during a boring vigilance task in which subjects were asked to respond to queries about spontaneous and deliberate thoughts as well as to the task itself. The results showed that ADHDs gave the highest numbers of spontaneous task-unrelated thoughts (TUTs) and false alarms and that left-eye dominance was related to childhood hyperactivity characteristics and to spontaneous TUTs. This suggested that ADHDs appeared to have distractions that were internal, rather than external, whereas the controls reported greater command of their thought processes. It appears that high levels of nonconscious processing from fleeting sensory input and/or previous thought emerge rapidly into consciousness as spontaneous thoughts. When ADHD individuals are bored, their semantic activation processes may seem more random and may cause discomfort to these individuals, resulting in poor coordination of attentional and inhibitional processes. It seems likely that unbidden, uncontrolled thoughts may be aversive to ADHD persons, leading them to behaviors that provide relief from such intrusions (i.e., extreme sensations, drug use, etc.).

\section{Unbidden Thought Is Common in ADHD and Creative People}

Shaw and Conway (1990) found that although semantically related conscious clues facilitated anagram solving in all subjects, high creatives used semantically related nonconscious clues to solve more anagrams more quickly than did low creatives. When a clue was presented below the threshold of awareness and semantic activation occured, the high creative felt that an idea had simply "popped into his head." If the idea was of immediate help, the anagram solution was facilitated; if not, the idea was ignored. In these experiments, high creatives also detected and identified words more quickly than did low creatives, but they also gave more false alarms. It was concluded that high-creative subjects were more tolerant of noisy or otherwise impoverished information from memory and the environment, less inhibited by nonconscious information, more willing to take risks, very tolerant of ambiguity, and more prepared to make decisions on the basis of less complete information. This may be a partial basis for apparent creative behavior.

The anagram task used in the present study was modeled after that used in the Shaw and Conway (1990) experiments with creatives. ADH children also responded by using more tacit clues than did controls. They, too, tolerated more ambiguous and incidental information and made use of it.

\section{Integrating Some Findings of ADHD and Creativity Studies}

It is possible to put together two very different findings: the indication of a specific deficit for ADHDs reported by Swanson et al. (1991) 
that causes focused attention to dissipate within a period of about $800 \mathrm{msec}$, and the Shaw and Conway (1990) result that high creatives process information below the level of awareness at very fast speeds. Indeed, the fastest clues presented tachistoscopically to subjects were given for a duration of $3 \mathrm{msec}$. Such priming of semantic activation occurs automatically and without effort or awareness.

If the methods of the Shaw and Conway (1990) work, and if the present study can be extrapolated to real-life situations, it is reasonable that both high-IQ ADHDs and high creatives gather information using more processes that are below the level of conscious awareness. Certainly, both types of subjects did, quickly and effortlessly, pick up and later use information that they could not recall seeing in the anagram task presented to them. Indeed, there is much evidence from other investigations that both creatives (see Bolton, 1972) and ADHD children (see Zentall \& Zentall, 1983) use broad scanning and less focused strategies in information gathering. It may be that the effects of rapid semantic activation processes, triggered by fleeting sensory input and/or previous thought, interfere with maintainence of attention and that they have learned to cope with their environments by using the skills that are available to them.

\section{An Integrated Model}

The following model may help to explain the behaviors of intelligent and creative ADHD persons. These individuals seek high-sensation and risk-filled situations, which, given their scattered information-gathering styles, leads to a divergent knowledge base. In these individuals, higher levels of nonconscious processing from tacit perception and/or previous thought and subsequent semantic activation are present. The results of these processes emerge into consciousness as spontaneous thoughts. When such persons are bored, which is a highly stressful and aversively arousing condition for them, they lack coordination of attentional and inhibitional processes, and their semantic activation processes are more random and may cause discomfort, resulting in poor concentration. When their interest is captured, higher arousal levels are again present, but semantic activation may be guided by internal and external cues, allowing smoother cognitive functioning. Thus these individuals exhibit poor inhibition and high impulsivity in situations of little interest to them and may gain "automatic control" only when interest is secured.

\section{Implications for the Study of ADHD}

Malone, Kershner, and Siegel (1988) tested the hypothesis that stimulant medication increases the ability to focus attention. In their discussion of the possible effects of the constriction of cognitive processing by stimulants, they noted evidence suggesting that stimulants cause ADHD children to canalize their attentional capacity, to become perseverative and lacking in flexibility, and to exhibit reduced curiosity and incidental learning. Malone et al. (1988) found that methylphenidate (ritalin) induced a left hemisphere advantage, which was interpreted as a normalization effect. The favorable therapeutic effect was produced through inhibition of excessive right brain activity in response to task demands that engaged the left hemisphere. Thus one ramification of stimulant medication appears to be that it takes some of these children out of the mode of processing information that is easiest for them. Therefore, childhood medication may be counter-productive for a lifetime of cognitive functioning that is based on strategies and knowledge gained earlier in life. Although the learning of language skills and concentrated effort must not be ignored, these children may be best served by being allowed to use their natural interests to achieve optimum arousal by means of the cognitive processes that they favor most.

\section{REFERENCES}

Bolton, N. (1972). The psychology of thinking. London: Methuen. Borcherding, B., Thompson, K., Kruesi, M., BartKo, J., RapoPORT, J., \& WEINGARTNER, H. (1988). Automatic and effortful processing in attention deficit/hyperactive disorder. Journal of $A b$ normal Child Psychology, 16, 333-345.

Bowers, K. (1984). On being unconsciously informed. In K. Bowers \& D. Meichenbaum (Eds.), The unconscious reconsidered (pp. 227272). New York: Wiley.

Conners, C. K. (1973). Rating scales for use in drug studies with children. Psychopharmacology Bulletin, 9, 24-84.
DenCKLA, M. (1979). Childhood learning disabilities. In K. Heilman \& E. Valenstein (Eds.), Clinical neuropsychology (pp. 535-573). New York: Oxford University Press.

Douglas, V. I. (1983). Attentional and cognitive problems. In M. Rutter (Ed.), Developmental neuropsychiatry (pp. 281-329). New York: Guilford.

GeschWind, N. (1984). The biology of cerebral dominance: Implications for cognition. Cognition, 17, 183-208.

Getzels, J. W. (1975). In I. A. Taylor \& J. W. Getzels, (Eds.), Perspectives in creativity (pp. 326-344). Chicago: Aldine.

LEVY, J. (1983). Language, cognition and the right hemisphere: A response to Gazzaniga. American Psychologist, 38, 538-541.

LogAN, G. D. (1989). Automaticity and cognitive control. In J. S. Uleman \& J. Bargh (Eds.), Unintended thought (pp. 52-74). New York: Guilford.

Malone, M., KerShNer, J., \& Siegel, L. (1988). The effects of methylphenidate on levels of processing and laterality in children with attention deficit disorder. Journal of Abnormal Child Psychology, 16, 379-395.

MendelsoHN, G., \& Griswold, B. (1964). Differential use of incidental stimuli in problem solving as a function of creativity. Journal of $A b$ normal \& Social Psychology, 68, 431-436.

Merrin, E. L. (1984). Motor and sighting dominance in chronic schizophrenics. British Journal of Psychiatry, 145, 401-406.

PoSNER, M. (1988). Structures and functions in selective attention. In T. Boll \& B. Bryant (Eds.), Clinical neuropsychology and brain function: Research, measurement and practice (pp. 169-202). New York: American Psychological Association.

PosNer, M., \& RothbarT, M. (1989). Intentional chapters on unintended thoughts. In J. S. Uleman \& J. Bargh (Eds.), Unintended thought (pp. 450-469). New York: Guilford.

Ross, D., \& Ross, S. (1982). Hyperactivity. New York: Wiley.

RUTTER, M. (1989). ADD/hyperkinetic Syndrome: Conceptual and research issues regarding diagnosis and classification. In T. Sagvolden \& T. Archer (Eds.), Attention deficit disorder (pp. 1-24). Hillsdale, NJ: Erlbaum.

SHAw, G. A. (1985). The use of imagery by intelligent and creative schoolchildren. Journal of General Psychology, 112, 153-171.

SHAw, G. A. (1986). Creativity and the cognitive unconscious. In Faculty Studies (Vol. 13, pp. 33-39). Georgetown, KY: Georgetown College.

SHAw, G. A. (1989). Laterality, implicit memory and creativity in attention deficit/hyperactivity disorder. Bulletin of the Psychonomic Society, 27, 487. (Abstract)

SHAw, G. A., \& Brown, G. (1990). Creativity, and laterality concomitants of attention problems. Developmental Neuropsychology, 6, 39-57.

SHAw, G. A., \& BROWN, G. (1991). Laterality, implicit memory and attention disorder. Educational Studies, 17, 1, 15-23.

Shaw, G. A., \& Conway, M. (1990). Individual differences in nonconscious processing: The role of creativity. Personality \& Individual Differences, 11, 407-418.

Shaw, G. A., \& Giambra, L. (in press). Task-unrelated-thoughts in college students diagnosed as hyperactive in childhood. Developmental Neuropsychology.

STERNBERG, R. (1985). Implicit theories of intelligence, creativity and wisdom. Journal of Personality \& Social Psychology, 49, 607-627.

Swanson, J., Posner, M., Potkin, S., Bonforte, S., Youpa, D., Fiore, C., Cantwell, D., \& Crinella, F. (1991). Activating tasks for the study of visual-spatial attention in ADHD children: A cognitive anatomic approach. Journal of Child Neurology, 6(Suppl.), 5119-5127.

TORRANCE, E. (1974). Torrance tests of creative thinking: Norms and technical manual. Princeton, NJ: Personnel Press.

Wallas, G. (1927). The art of thought. New York: Harcourt Brace.

YANIV, I., \& MEYER, D. (1987). Activation and metacognition of stored information. Journal of Experimental Psychology: Learning, Memory, \& Cognition, 13, 187-205.

Zentall, S. S., \& Zentall, T. R. (1983). Optimal stimulation: A model of disordered activity and performance in normal and deviant children. Psychological Bulletin, 94, 446-471.

ZINBARG, R. (1987). Sidedness, health disorders and aptitudes (Tech. Rep. 1987-2). Boston: Johnson O'Conner Research Foundation.

ZuCKerman, M. (1979). Sensation seeking: Beyond the optimal level of arousal. Hillsdale, NJ: Erlbaum.

(Manuscript received October 28, 1991.) 